\title{
Inclusão reversa e voleibol sentado: direitos humanos em jogo
}

https://doi.org/10.11606/issn.1981-4690.v35inespp1-6

\author{
Maria Denise Dourado da Silva* \\ Layana Costa Ribeiro Cardoso** \\ Dulce Maria Filgueira de Almeida*
}

*Universidade de

Brasília, Brasília, DF

Brasil.

**Instituto Federal do

Amapá, Macapá, AP,

Brasil.

\section{Resumo}

0 presente artigo tem por objetivo apresentar a Inclusão Reversa e os sentidos de corpo com deficiência como possivel estratégia pedagógica para o ensino no contexto de aulas de Educação Física. Os termos "Inclusão Reversa" e "corpo com deficiência" foram identificados por meio de pesquisa bibliográfica, realizada em livros e artigos científicos no período compreendido de 2000 a 2020. Complementarmente, foram consultadas as legislações a respeito. Verificou-se que, além de possuirmos legislação adequada ao tema, há um avanço, em termos da literatura científica, para a adoção de termos como corpo com deficiência e Inclusão Reversa, como estratégia pedagógica. 0 desafio contingente à Educação Física se refere ao projeto de formação de professores comprometido com uma preparação pedagógico-didática que assegure domínio de conhecimentos necessários à compreensão da realidade social, tendo em vista que as necessidades, os interesses e as condições não são iguais para todos.

PalavRas-Chave: Corpo com deficiência; Formação de professores; Estratégia pedagógica; Educação física inclusiva.

\section{Introdução}

Dados da Organização Mundial da Saúde ${ }^{1}$ mostram que a população mundial de pessoas com deficiência ultrapassa um bilhão. No Brasil, o Instituto Brasileiro de Geografia e Estatística ${ }^{2}$ afirma que temos 45 milhóes de pessoas com deficiência. Esses resultados, por si, são suficientes para que os olhos sejam voltados para as questóes que interferem diretamente na qualidade dessas vidas e que pesquisas que versam sobre a temática sejam realizadas.

O presente artigo tem por objetivo apresentar a Inclusão Reversa e os sentidos de corpo com deficiência como possível estratégia pedagógica para o ensino no contexto de aulas de Educação Física. Os termos "Inclusão Reversa" e "corpo com deficiência" foram identificados por meio de pesquisa bibliográfica, realizada em livros e artigos científicos no período compreendido de 2000 a 2020. Complementarmente, foram consultadas as legislaçóes a respeito, incluindo-se a Constituição Federal ${ }^{3}$.

Vale observar que entendemos Inclusão Reversa como uma prática que se constitui pela mudança de posições ou papéis no contexto das aulas de Educação Física, em que colocamos estudantes com condição física típica em situaçóes educacionais direcionadas a pessoas com deficiência, por intermédio da implementação da disciplina Voleibol Sentado. As questóes afetas à dimensão conceitual desta modalidade paralímpica foram exploradas a partir da leitura do artigo: "Inclusão e Exclusão no contexto da Educação Física escolar" o quanto, na trajetória histórica da Educação Física brasileira, as pessoas com deficiência foram excluídas do processo educacional e, consequentemente, do pleno exercício de seus direitos. Por sua vez, o o corpo com deficiência será visto por meio de um conceito mais ampliado como construção social, mediado por fatores biopsicossociais, aliando-se, nesse escopo, às perspectivas teóricas de Le BRETON ${ }^{5}$ e de Mauss 6 .

$\mathrm{O}$ interesse em desenvolver este estudo partiu de dois aspectos. O primeiro, da prática pedagógica, pois uma das autoras atuou como professora substituta de uma instituição federal de ensino superior com a disciplina Metodologia do Voleibol, em que um dos seus conteúdos foi o Voleibol Sentado. O segundo aspecto, para além da experiência docente, deu-se em decorrência da imersão no universo da pesquisa, dedicando-se à pesquisa de doutorado acerca do Corpo Feminino com Deficiência, a qual tem como locus de investigação um grupo social composto 
por mulheres jogadoras de Voleibol Sentado. Esses dois aspectos evidenciaram a necessidade de problematizar a prática docente, as estruturas físicas das instituiçóes de ensino superior, bem como os sentidos que possui o corpo com deficiência e a Inclusão Reversa nestes contextos acadêmicos. A nosso ver, trata-se de um compromisso ético-político fundamental na formação humanística que se quer no ensino superior, notadamente naquela direcionada à formação de futuros professores de Educação Física.

\section{Corpo com deficiência e inclusáo reversa: jogando com os direitos humanos}

As práticas pedagógicas realizadas na modalidade esportiva denominada Voleibol Sentado podem oferecer oportunidades de todos os atores sociais envolvidos (professor/a e discentes com ou sem deficiência) se identificarem e se sensibilizarem mutuamente, reconhecendo que todos são possuidores de algum nível de dificuldade conforme a atividade a ser desenvolvida e de acordo com as regras que deverão ser seguidas.

\section{a) Legislaçôes no Brasil}

Em nossa consulta, do ponto de vista normativo, identificamos um conjunto de enunciados que favorecem o reconhecimento, pelo Estado brasileiro, de direitos para a pessoa com deficiência. $\mathrm{O}$ primeiro marco surge da própria Constituição Federal ${ }^{3}$, a qual trata do tema em vários artigos, inclusive por meio de emendas que buscaram atender ao princípio da "plena e efetiva participaçáo e inclusão na sociedade", previsto na Convenção Internacional sobre o Direito das Pessoas com Deficiência, assinado pela República Federativa do Brasil em Nova Iorque, em 30 de março de 2007.

$\mathrm{O}$ segundo documento legal identificado em nossa consulta é o Decreto n. 6949, de 25 de agosto de 2009, posteriormente reconhecido no artigo $4^{\circ}$ da Lei n. 13146, de 6 de julho de 2015, garantindo, ao menos na lei, que a pessoa com deficiência será tratada com "igualdade de oportunidades com as demais pessoas e não sofrerá nenhuma espécie de discriminaçẫo"7.

De fato, o Brasil possui um arcabouço normativo bastante inclusivo, tratando do tema em 12 (doze) artigos $^{3}$ da Constituição Federal promulgada em outubro de 1988 e avançando por várias leis posteriormente publicadas, até a recente Lei no 13146/2015, que instituiu a Lei Brasileira de Inclusão da Pessoa com Deficiência, o denominado
Estatuto da Pessoa com Deficiência. Soma-se a isso o fato de que o artigo 24, inciso XIV, da CF/1988 preconiza que compete à Uniáo, aos Estados e ao Distrito Federal legislar concorrentemente sobre "proteção e integração social das pessoas portadoras de deficiência", gerando consequentemente mais normas voltadas ao alcance dos anseios populares e à efetividade dos comandos enunciados pela Assembleia Nacional Constituinte de 1987. Queremos dizer com isso que o problema imediato e atual é a inobservância das regras do jogo, isto é, a quase inaplicabilidade - ou implementação incipiente das leis federais, estaduais e municipais que tratam da proteção, da integração ou da acessibilidade de pessoas com deficiência, incapazes de promover efetivamente a conjuntura favorável para que elas atuem em condições de igualdade em diversos campos da vida em sociedade.

Diante das exigências legais vigentes, o que se identifica na prática é que há, por parte das instituiçóes de ensino públicas e privadas, quando muito, um aparente cumprimento de requisitos mínimos aderentes às cobranças normativas, como um preenchimento de itens em um check list, numa espécie de aferição do custo versus benefício.

SCHOGER ${ }^{8}$, ao tratar das oportunidades de inclusão em ambiente escolar, embora trate de programa aplicado nos Estados Unidos da América, em realidade diversa da brasileira, igualmente registra que há a "falta de pessoal qualificado, logistica, programação e outras dificuldades". Portanto, verifica-se que a despeito de haver legislação, avalia-se quanto se deve investir na adaptação de um logradouro ou em uma instalação, em correlação com uma previsão de quantas pessoas com deficiência frequentariam aquele ambiente. Acresce-se a esse quadro, em uma relação recursiva de causas e efeitos, a mesma realidade discutida por situação identificada em nosso país.

Há, portanto, uma ineficácia dos meios destinados ao cumprimento da legislação, como elevadores que não funcionam, calçamentos com inclinaçôes excessivas, pisos escorregadios ou o despreparo de profissionais que deveriam ser sensibilizados e treinados para lidar com os recursos disponíveis, como motoristas de transporte público que eventualmente não sabem operar uma plataforma elevatória de um ônibus, quando elas funcionam. É nesse contexto que se inserem os professores de Educação Física, não confrontados em sua formação com as necessidades próprias dessa parcela da população denominada "pessoas com deficiência", entendendo-as como uma exceção que não será encontrada no cotidiano escolar. 
Nesse contexto, emerge que o problema náo é a falta de legislação, mas a constatação de que a política de inclusão das pessoas com deficiência encontra barreiras diante da "falta de pessoal qualificado, logística, programação e outras dificuldades encontradas ao tentar atender às necessidades específicas dos alunos no ambiente de educação geral" ${ }^{8}$, tornando mais uma vez a atividade educacional uma importante forma de conscientização e de reconhecimento dos fatores limitadores ao pleno exercício da cidadania por todos os componentes da sociedade, bem como impondo o enfrentamento dessas condiçóes pelas instituições e seus integrantes.

b) Conceito de "deficiência" e corpo com deficiência: para além do biomédico

No que concerne ao termo e significado de deficiência alocado no modelo social, identificamos como principal marco teórico Diniz", para quem tratar da deficiência: "essencialmente é uma questão de direitos humanos". Neste sentido, os impedimentos corporais em si não são determinantes do nível de participação social, mas o seu significado na experiência da interação social, a exemplo das condiçóes de acessibilidade. De acordo com Mello e NuernBerg ${ }^{10}$, este modelo social subverteu a lógica do modelo biomédico ao confrontar a afirmação de que a deficiência é imposta pela natureza ao impor desvantagens ao corpo com deficiência e a limitar sua participação na sociedade em uma relação de causalidade. De maneira mais complexa, a deficiência foi relacionada ao contexto das estruturas sociais que aprofundam as restrições das experiências do corpo com deficiência com suas barreiras arquitetônicas, com sua ordem simbólica e ou atitudinal.

Outro autor que pode ser destacado e servir como referência para os estudos de corpos com deficiência é LE BRETON 5 . Segundo ele, a relação social estabelecida com o corpo com deficiência é ambígua diante do discurso social de que o mesmo não tem sua dignidade e valor enfraquecidos, mas ao mesmo tempo homologa seu distanciamento e participação na comunidade por dificuldades no deslocamento e de acesso decorrentes de barreiras estruturais e simbólicas. Conhecer os diferentes significados construídos sobre o corpo nos faz refletir sobre o tema e compreender as relações que a sociedade tem estabelecido com o corpo com deficiência, a partir de aproximaçáo aos modelos de deficiência que se apontam: modelo religioso, em que o corpo com deficiência representa um castigo divino; modelo caritativo, isto é, o corpo com deficiência sendo visto como digno de benevolência; modelo médico, tendo o corpo visto como falha corporal que precisa ser tratada para reabilitação do indivíduo; e modelo social da deficiência, em que ela se associa à interação com a estrutura social histórica e culturalmente construídas para não acolher a diferença. Essas distintas visões não aconteceram em um caráter evolucionista, pois elas coexistem e se misturam, inclusive dentro da mesma geração.

c) Inclusão reversa: uma proposição da prática pedagógica inclusiva

Quanto à Inclusão Reversa, destacamos dois autores relevantes: BAKER ${ }^{11}$ e YAMAGUTI ${ }^{12}$. BAKER ${ }^{11}$, por exemplo, afirma que "Inclusão Reversa é um programa de interaçáo planejada com alunos em desenvolvimento típico da população de educação geral que trabalham com alunos com deficiência de moderada a grave em uma sala de aula de educação especial independente". YAMAGUTi ${ }^{12}$, de outro lado, conceitua Inclusão Reversa como "processo de inclusão em que o indivíduo sem deficiência participa de programas específicos para a pessoa com deficiência”, enfoque que será adotado na presente discussão.

No paradigma da Inclusão Social é a sociedade que se adapta às pessoas com deficiência, provendo-lhes acessibilidade. Ao contexto sociocultural, como elemento constitutivo da deficiência, caberá a responsabilidade de prover os meios para que as pessoas com deficiência participem da vida coletiva, recuperem a dignidade e exerçam a cidadania.

Com essa premissa, Inclusão Reversa na prática escolar aqui se apresenta como um efetivo projeto de imersão de pessoas ditas "sem deficiência" nesse novo universo repleto de limitaçóes estruturais, metodológicas, comunicacional, programáticas (políticas públicas, normas e regulamentos) e circunstanciais ${ }^{13}$ que culminam em um processo de estigmatizaçáa ${ }^{14}$ de um grupo como de "pessoas com deficiência", afetadas no exercício pleno da cidadania. O último autor diz que a relação estabelecida entre atributo e estereótipo leva a uma abominaçáo do corpo com deformidades e sua consequente condenação a viver sem exercer seus direitos de cidadão.

Com o fomento desse processo, cria-se igualdade de condiçóes entre os atores sociais com ou sem deficiência, os quais terão de aprender técnicas corporais $^{6}$ específicas e táticas em um cenário de interação lúdico e ao mesmo tempo sensibilizador, propiciando a compreensão de que a pessoa se identifica "com" ou "sem" deficiência ${ }^{15}$ conforme as circunstâncias apresentadas e de acordo com o jogo simbólico e suas regras previamente estabelecidas. 
Observamos assim que atores sociais distintos aqui, pessoas com e sem deficiência - possuem mais aptidão a prosperar (ou não) ou a ter mais ou menos dificuldade na realização de determinadas atividades conforme o sistema normativo vigente a ser seguido prestigie as características de um grupo em detrimento do outro.

É com essa premissa que se identifica que a realizaçáo do processo de ensino - dentro de pressupostos teórico-metodológicos heterogêneos e comprometidos com a aprendizagem de todos e que apresente e estabeleça um conjunto de regras (aqui, as regras do Voleibol Sentado) que atenda às peculiaridades e às condiçóes do ator social dito "com deficiência" - culmina por colocá-los em condiçóes de igualdade adaptativa e competitiva perante colegas discentes que normalmente não possuem algum

\section{Considerações finais}

Nosso objetivo foi apresentar a Inclusão Reversa e os sentidos de corpo com deficiência como possíveis estratégias pedagógicas para o ensino no contexto de aulas de Educação Física. Os termos "Inclusão Reversa" e "corpo com deficiência" foram identificados por meio de pesquisa bibliográfica, realizada em livros e artigos científicos no período compreendido de 2000 a 2020. Complementarmente, foram consultadas as legislaçôes a respeito, incluindo-se a Constituição Federal ${ }^{3}$.

É nesse contexto que se identifica que o problema reside, ao menos no Brasil, na inaplicação da legislação já vigente ${ }^{3}$ e não no fato de ela não existir ou de as leis prestigiarem apenas um ator social em detrimento do outro. $\mathrm{O}$ tema da acessibilidade foi elevado ao status de garantia constitucional prevista desde a promulgação da Constituição Federal $^{3}$, porém em artigo de conteúdo programático (art. 244), isto é, uma norma que para atingir eficácia demanda a regulamentaçáo por meio de outra, a lei. As primeiras normas regulamentadoras começaram a ser publicadas em dezembro de 2000 até a publicação do já citado Estatuto da Pessoa com Deficiência e até a presente data não se verifica eficácia plena.

Dentro dessa perspectiva, o Voleibol Sentado se apresenta, portanto, como uma prática corporal com importância reconhecida para o exercício legítimo de direitos fundamentais das pessoas com deficiência, em que poderão desenvolver suas potencialidades, tanto no sentido de autorrealização, como em sua tipo de restrição ou limitação em seus movimentos, convergindo com a máxima de autoria atribuída a Aristóteles de que "igualdade é tratar igualmente os iguais e desigualmente os desiguais, na medida de sua desigualdade" e tornando ambos os atores "iguais" para o desempenho das atividades naquele ecossistema.

A breve discussão da submissão das pessoas às regras do jogo conduziria a uma primeira constataçáo de que as dificuldades encontradas no cotidiano por uma pessoa com algum tipo de característica física, inata ou adquirida, limitadora de sua locomoçáo seriam decorrentes de uma inadequação do sistema normativo vigente (as leis e a Constituição do país), que prestigiaria com seu código de conduta pessoas sem deficiência em detrimento das que possuem algum tipo de limitação de qualquer natureza. Não é efetivamente o que se verifica na realidade brasileira.

identificação como cidadáo pleno e, por outro lado, despertar a consciência dos discentes com e sem deficiência à necessidade de tornar as atitudes inclusivas uma realidade.

No Voleibol Sentado como disciplina acadêmica dos cursos de formação de professores de Educação Física, a Inclusão Reversa poderá ser implementada como forma de recuperar a defasagem em relação aos conteúdos que preparam os professores para trabalhar com essa parcela da populaçấo e importante recurso no aprimoramento das sofisticadas técnicas corporais próprias da modalidade - a exemplo do deslocamento - bem como dos componentes pedagógico, humano e ontológico.

Discutindo os desafios a que se está exposto, apontamos a Inclusão Reversa tanto como estratégia pedagógica, quanto como conteúdo dentro de uma perspectiva metodológica que subsidie o desenvolvimento de ação educativa voltada ao cumprimento de objetivos educacionais da escola democrática que venham a incluir os alunos com deficiência dentro do processo ensino-aprendizagem e a atingir a meta do projeto educativo, ao realizar uma mudança de atitude dos atores sociais frente às pessoas com deficiência.

Ao final, nossa intenção é propor o ensino do Voleibol Sentado, modalidade esportiva paralímpica, como uma disciplina dos cursos de graduação em Educação Física, focada no fomento de uma mentalidade que poderá contribuir, com emprego 
de atividades de Inclusão Reversa, no preparo dos professores para atuarem com grupos heterogêneos. Acreditamos na conscientização e na modificação $\mathrm{da}$ postura da sociedade frente às pessoas com deficiência, compreendendo-as como atores sociais detentores de direitos e de condiçóes iguais. como perspectiva importante para a mudança de mentalidade mencionada.

O desafio contingente à Educação Física se refere ao projeto de formação de professores comprometido com uma preparaçáo pedagógico-didática que assegure domínio de conhecimentos necessários à compreensão da realidade social, tendo em vista que as necessidades, os interesses e as condiçóes dos discentes não são iguais para todos. No caso das pessoas com deficiência, tais particularidades requerem qualificação acadêmica do professor no tocante ao planejamento e à execução de práticas educativas que resultem no desenvolvimento de suas potencialidades com consequentes ganhos em habilidades motoras e sociais, bem como no sentimento de reconhecimento social e de respeito de seus direitos.

\begin{abstract}
Reverse inclusion and sitting volleyball: human rights at stake

This article aims to present the reverse inclusion and the meanings of the body with disabilities as a possibility of pedagogical strategy for teaching in the context of Physical Education classes. The terms "reverse inclusion" and "body with disabilities" were identified through bibliographic research, carried out on books and scientific articles in the period from 2000 to 2020. In addition, the relevant legislation was consulted. It was found that, in addition to having legislation appropriate to the theme, there is an advance, in terms of scientific literature, for the adoption of terms such as body with disabilities and reverse inclusion, as a pedagogical strategy. The contingent challenge to Physical Education refers to the teacher training project committed to a pedagogical-didactic preparation that ensures mastery of the knowledge necessary to understand the social reality, considering that the needs, interests and conditions are not the same for everyone.
\end{abstract}

KEYwORDs: Body with disability; Teaching formation; Pedagogical strategy; Inclusive physical education.

\title{
Referências
}

1. Organização Mundial da Saúde. Relatório mundial sobre a deficiência [Internet]. 2011. 360 p. Disponível em: http://whqlibdoc.who.int/publications/2011/9788564047020_por.pdf?ua=1.

2. Instituto Brasileiro de Geografia e Estatística. Características gerais da população, religião e pessoas com deficiência. Censo demográfico 2010 [Internet]. 2010;1-215. Disponível em: https://biblioteca.ibge.gov.br/visualizacao/ periodicos/94/cd_2010_religiao_deficiencia.pdf.

3. Constituição da República Federativa do Brasil. Brasília, DF. J Comput. 1988;1903-12.

4. Chicon JF. Inclusão e exclusão no contexto da Educação Física escolar. Mov. 2008;14(1):13-38.

5. Le Breton D. A Sociologia do corpo. 6th ed. Petropolis: Vozes; 2012.

6. Mauss M. Sociologia \& antropologia. Cosac Naify. 2017;7(1).

7. Brasil. Lei 13.146, de 6 de julho de 2015. Institui a Lei Brasileira de Inclusão das Pessoas com Deficiência (Estatuto da Pessoa com Deficiência). Diário Oficial da Uniáo 2015; 7 jul.

8. Schoger KD. Reverse inclusion: providing peer social interaction opportunities to students placed in self-contained special education classrooms. Teach Except Child Plus [Internet]. 2006;2(6):11. Disponível em: http://ezproxy.library.yorku.ca/ login?url=http://search.proquest.com/docview/1023530526?accountid=15182.

9. Diniz D, Barbosa L, Santos WR dos. Deficiência, direitos humanos e justiça. Sur Rev Int Direitos Humanos. 2009;6(11):64-77.

10. Mello AG, Nuernberg AH. Gênero e deficiência: Interseçôes e perspectivas. Rev Estud Fem. 2012;20(3):635-55.

11. Baker LK. Implications of a Reverse Inclusion Program for Students with Moderate to Severe Disabilities. Capstones Theses Pap 503 [Internet]. 2015; Disponível em: http://digitalcommons.csumb.edu/caps_thes Recommended. 
12. Yamaguti Y. Inclusão reversa: saiba como é e entenda os benefícios de pessoas com e sem deficiência [Internet]. 2013. Disponível em: https://apnendenovaodessa.blogspot.com/2013/03/inclusao-reversa-saiba-como-e-e-entenda.html

13. Sassaki RK. Inclusão: construindo uma sociedade para todos. Rio Janeiro. 2006;7.

14. Goffman E. Estigma: notas sobre a manipulação da identidade deteriorada. TLC. 2012.

15. Ribas JBC. O que são pessoas deficientes. Brasiliense. 2003.

\begin{tabular}{r|r} 
ENDEREÇO & \\
Maria Denise Dourado da Silva & \\
Universidade de Brasília & Recebido: 04/01/2021 \\
Faculdade de Educação Física & Aceito: 06/ 01/2021 \\
Campus Universitário Darcy Ribeiro - Asa Norte & \\
70919-970 - Brasília - DF - Brasil & \\
E-mail: mdedourado@gmail.com &
\end{tabular}

Rev Bras Educ Fís Esporte, (São Paulo) 2021J unho;35(nesp):1-6 